\title{
Diagnostic Value of Narrow Band Imaging in Diagnosing Nasopharyngeal Carcinoma
}

\author{
Debbi Yuniserani, ${ }^{1}$ Bethy S. Hernowo, ${ }^{2}$ Agung Dinasti Permana ${ }^{3}$ \\ ${ }^{1}$ Faculty of Medicine Universitas Padjadjaran, ${ }^{2}$ Department of Anatomical Pathology Faculty of \\ Medicine Universitas Padjadjaran/Dr. Hasan Sadikin General Hospital Bandung, ${ }^{3}$ Department of \\ Otorhinolaryngology-Head and Neck Surgery Faculty of Medicine Universitas Padjadjaran/Dr. \\ Hasan Sadikin General Hospital Bandung
}

\begin{abstract}
Background: Carcinoma is the most common tumor in nasopharynx. Endoscopy is used to determine the presence of lesions suspected of malignancy. Narrow Band Imaging is an endoscopic technique that uses narrow-band spectrum as a filter to determine any mucosal vascular changes in carcinoma. Narrow Band Imaging can early detect superficial mucosal lesions that are difficult to detect with conventional endoscopy, so that diagnosing is more accurate and occurrence of unnecessary biopsies can be reduced. This study aimed to determine diagnostic value of Narrow Band Imaging in diagnosing nasopharyngeal carcinoma.

Methods: This diagnostic test study was conducted at Department of Otorhinolaryngology-Head and Neck Surgery Dr. Hasan Sadikin General Hospital, Bandung from September to October 2014. Twenty four patients with clinical signs and symptoms of nasopharyngeal carcinoma that fulfilled the study criteria were assigned using consecutive sampling to examine with Narrow Band Imaging and histopathology examination. The data were then analyzed with $2 \times 2$ table to determine sensitivity, specificity, positive predictive value, negative predictive value, and accuracy.

Results: In this study, the results of sensitivity, specificity, positive predictive value, negative predictive value, and accuracy in diagnosing nasopharyngeal carcinoma using Narrow Band Imaging were 93.75\%, $62.5 \%, 83.3 \%, 83.3 \%$, and $83.3 \%$, respectively.

Conclusions: Sensitivity of Narrow Band Imaging is 93.75\%. [AMJ.2017;4(1):133-7]
\end{abstract}

Keywords: Diagnostic test, narrow band imaging, nasopharyngeal carcinoma

\section{Introduction}

Carcinoma is type of tumor that is mostly discovered in nasopharynx. In Indonesia, prevalence of nasopharyngeal carcinoma is about 6 cases per 100,000 with 12,000 new cases per year. Nasopharyngeal carcinoma is one of five highest frequencies of malignancy in Indonesia. ${ }^{1}$ It is often discovered in adult than children and the increasing starts at the age 30 with peak age between 40 and 60 years old. ${ }^{2,3}$ Nasopharyngeal carcinoma is also more common in men than women with ratio $2-3: 1{ }^{3}$

Difficulty in diagnosing nasopharyngeal carcinoma from clinical symptom often happens because the location of nasopharynx and the symptom is not specific. ${ }^{4}$ Definitive diagnosis that is used for nasopharyngeal carcinoma is biopsy-endoscope combination. ${ }^{5}$ Endoscopy is usually used to detect any possible malignancy of lesion. ${ }^{5}$ However, conventional endoscopy has limitation in detecting superficial lesion that makes unnecessary biopsy often happen. ${ }^{6,7}$ Narrow Band Imaging is an endoscope technique that uses narrow-band spectrum as a filter to increase the visualization of vascular pattern. Narrow Band Imaging can detect superficial lesion, so that unnecessary biopsy can be reduced. ${ }^{7,8}$ Although study about Narrow Band Imaging is increased like in digestive system, it is not in head-neck region including nasopharynx. ${ }^{9}$ This study aimed to determine the diagnostic value of Narrow Band Imaging in diagnosing nasopharyngeal carcinoma.

\section{Methods}

This study was a diagnostic test study with histopathology as a gold standard. Sampling

Correspondence: Debbi Yuniserani, Faculty of Medicine, Universitas Padjadjaran, Jalan Raya Bandung-Sumedang Km.21, Jatinangor, Sumedang, Indonesia, Phone: +62 83816734032 Email: serra_debb@yahoo.com 

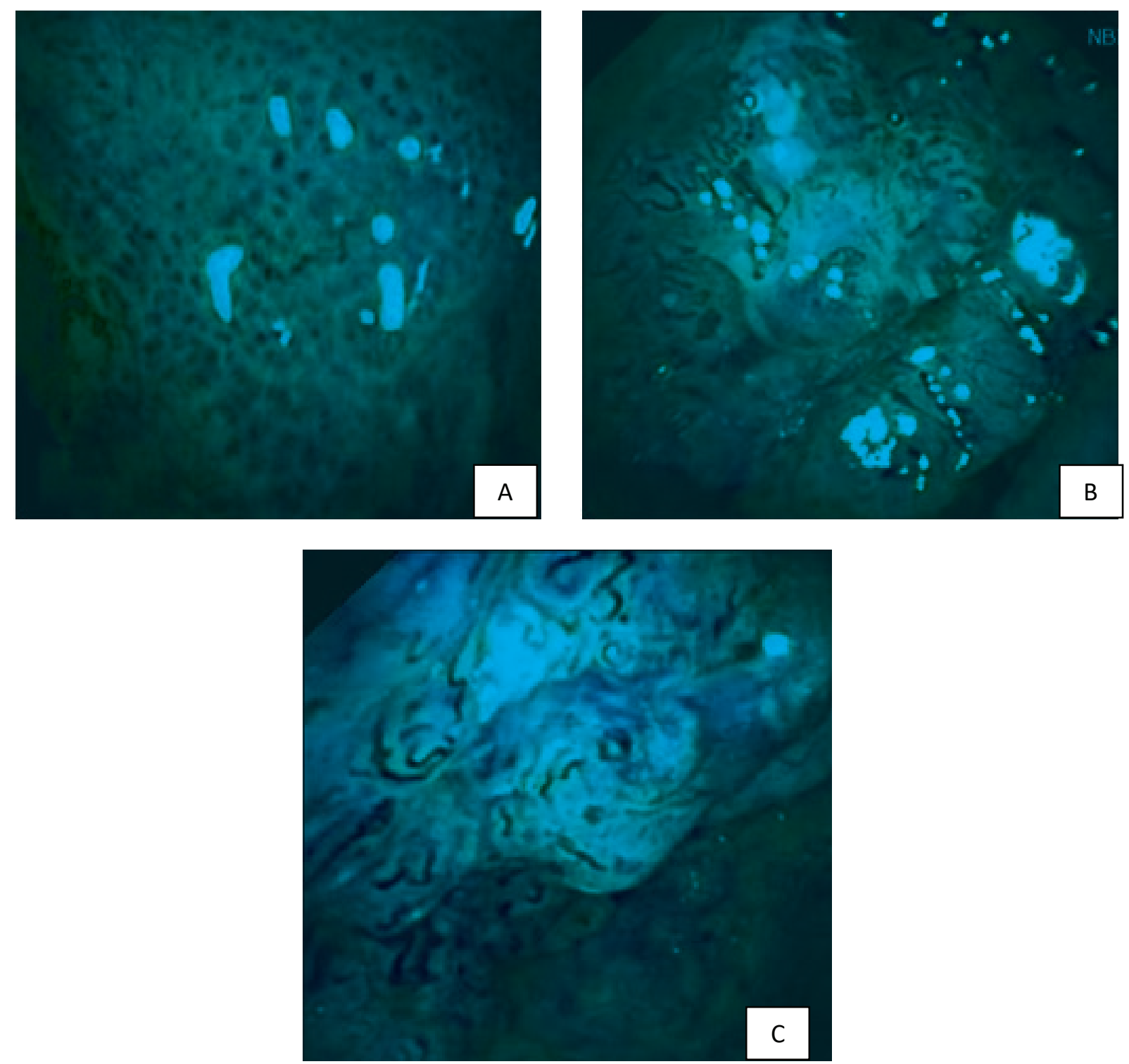

Figure 1 Nasopharyngeal Carcinoma (+) a. Brownish Spot, b\&c. Irregular Vascular Pattern with Brown Spot

technique was a consecutive sampling method with sample size was 24 samples. This study was conducted from September 1 to October 31 , 2014 at Department of OtorhinolaryngologyHead and Neck Surgery, Dr. Hasan Sadikin General Hospital, Bandung and was approved by Health Research Ethics Committee.

Population of this study was patients with clinical signs and symptoms of nasopharyngeal carcinoma at Department of Otorhinolaryngology-Head and Neck Surgery, Dr. Hasan Sadikin General Hospital, Bandung. Inclusion criteria were new cases of suspected nasopharyngeal carcinoma, while exclusion criteria were patients with 1) recurrent nasopharyngeal carcinoma, 2) history of radioteraphy, 3) history of hematologic diseases, and 4) history of biopsy in nasopharynx.

After informed consent, the subjects were given nasal decongestion containing lidocaine $10 \%$. Then, they were examined with Narrow Band Imaging through nose and mucosa of nasopharynx that were obsessed and assessed based on predetermined criteria. Positive criteria of Narrow Band Imaging are: 1) absence of the normal pattern of nasopharyngeal mucosa, 2) irregular vascular pattern with 

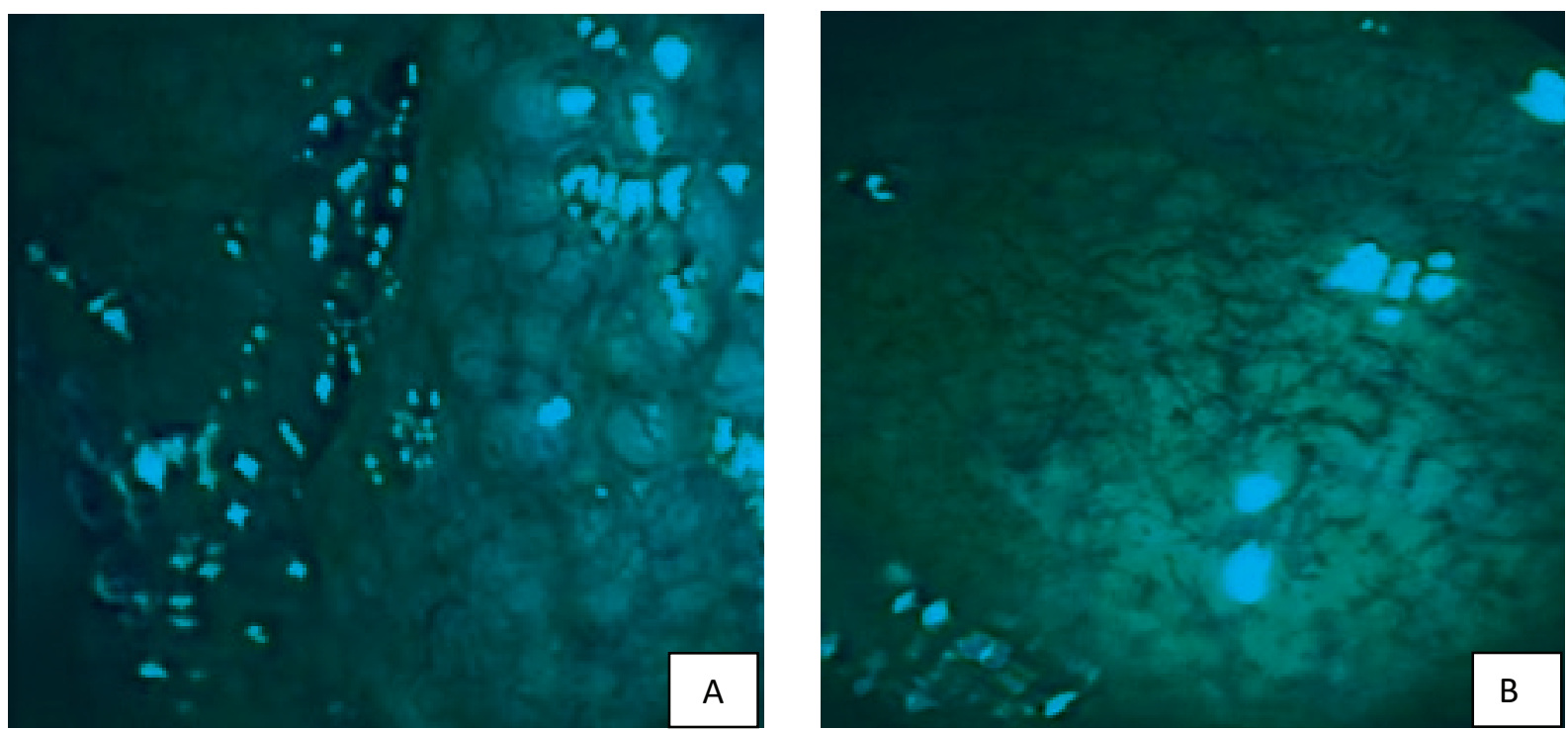

Figure 2 Nasopharyngeal Carcinoma (-) a. Regular Follicle Pattern, b. Regular Vascular Pattern

brown, and/or 3) irregular follicle pattern with pale peripheral and central brownish. Negative criteria of Narrow Band Imaging are: 1) regular follicle pattern, 2) pale central and dark peripheral follicle pattern. ${ }^{10}$ Biopsy procedures would be conducted and samples were examined histopathologically. Data from both examinations that had been collected would be tabulated and converted into $2 \times 2$ tables to determine sensitivity, specificity, positive predictive value, negative predictive value, and accuracy.

\section{Results}

Data characteristics including age group and sex can be seen in Table 1 and Table 2 . The data were divided into two groups; carcinoma and non-carcinoma based on histopathological diagnosis. In carcinoma group, there were 1) non-keratinizing and undifferentiated nasopharyngeal carcinoma. Meanwhile, in non-carcinoma group, there were lymphoma and inflammation of the nasopharynx.

Generally, the highest frequencies were from age group 41-50 years and 51-60 years, which consist of 7 subjects each, and the lowest frequencies were from the age group 61-70 years old and 81-90 years, which consist of 1 subject each. In carcinoma cases, the most common was revealed from age group 41-50 years, which consists of 7 subjects.

From all cases, the sex characteristics were

Table 1 Age Group Characteristics

\begin{tabular}{lccc}
\hline \multirow{2}{*}{ Age Group } & \multicolumn{2}{c}{ Histopathology } & \multirow{2}{*}{ Total } \\
\cline { 2 - 4 } & Carcinoma & Non-Carcinoma & 3 \\
\hline$<31$ & 2 & 1 & 3 \\
$31-40$ & 2 & 1 & 7 \\
$41-50$ & 7 & 0 & 7 \\
$51-60$ & 4 & 3 & 1 \\
$61-70$ & 1 & 0 & 2 \\
$71-80$ & 0 & 2 & 1 \\
$81-90$ & 0 & 1 & 24 \\
Total & 16 & 8 & \\
\hline
\end{tabular}


Table 2 Sex Characteristics

\begin{tabular}{|c|c|c|c|}
\hline \multirow{2}{*}{ Sex } & \multicolumn{2}{|c|}{ Histopathology } & \multirow{2}{*}{ Total } \\
\hline & Carcinoma & Non-Carcinoma & \\
\hline Man & 10 & 6 & 16 \\
\hline Woman & 6 & 2 & 8 \\
\hline Total & 16 & 8 & 24 \\
\hline
\end{tabular}

Table 3 Diagnostic Values

\begin{tabular}{lccc}
\hline \multirow{2}{*}{ Narrow Band Imaging } & \multicolumn{2}{c}{ Histopathology } & \multirow{2}{*}{ Total } \\
\cline { 2 - 4 } & Positive & Negative & 18 \\
\hline Positive & $15^{(\text {a) }}$ & $3^{(\mathrm{b})}$ & 6 \\
Negative & $1^{(\mathrm{c})}$ & $5^{(\mathrm{d})}$ & 24 \\
Total & 16 & 8 & \\
\hline
\end{tabular}

higher in men (16 samples) than women (8 samples).

In this study, the sensitivity was $93.75 \%$, specificity was $62.5 \%$, positive predictive value was $83.3 \%$, negative predictive value was $83.3 \%$, and accuracy was $83.3 \%$.

\section{Discussion}

From 16 nasopharyngeal carcinoma patients, most of subjects were from age group 41-50 years old consisting of male patients (10 samples) which was higher than female patients (6 samples). These data are similar to literatures that mention the age peak-of nasopharyngeal carcinoma at the age 40-60 years and more common happen in men than women. ${ }^{2,3}$ Nasopharyngeal carcinoma is more common in men, which is caused by prolonged exposure to risk factor like smoking which can increase the disease. ${ }^{11,12}$

In this study, the sensitivity was $93.75 \%$, specificity was $62.5 \%$, positive predictive value was $83.3 \%$, negative predictive value was $83.3 \%$, and accuracy was $83.3 \%$. The sensitivity result showed that ability of Narrow Band Imaging to detect patients with nasopharyngeal carcinoma is about $93.75 \%$. This result is similar to Wang' ${ }^{13}$ study that the result is about $97.1 \%$ and Wen's ${ }^{14}$ study that the result is about 93.9\%. Specificity result showed that ability of Narrow Band Imaging to eliminate patients with non-nasopharyngeal carcinoma is about $62.5 \%$. Compared to previous studies (Wang ${ }^{13}$ is $93.33 \%$ and Wen ${ }^{14}$ is $94.1 \%$ ), the specificity from this study is lower. Thus, it might be due to inability of Narrow Band Imaging to differ types of malignancy (like lymphoma and carcinoma) or total of sample is less compared to previous studies.

Positive predictive value result showed that the probability of subjects with positive Narrow Band Imaging will actually have nasopharyngeal carcinoma by $83.3 \%$. Negative predictive value result showed that the probability of subjects with negative Narrow Band Imaging will actually not have nasopharyngeal carcinoma by $83.3 \%$. Both values are also similar to previous studies. ${ }^{13,14}$ Accuracy result showed that the accuracy of Narrow Band Imaging in the diagnosing of nasopharyngeal carcinoma is $83.3 \%$.

Based on this study, it can be concluded that the sensitivity of Narrow Band Imaging is 93.75\%.

Limitation of this study was the samples used in this study were too small that affect Narrow Band Imaging value. In addition, subjects in this study were mostly at late stage.

It is recommended for further study to discuss about Narrow Band Imaging in wider population.

\section{References}

1. Adham M, Kurniawan AN, Muhtadi AI, Roezin A, Hermani B, Gondhowiardjo $\mathrm{S}$, et al. Nasopharyngeal carcinoma in Indonesia: epidemiology, incidence, signs, and symptoms at presentation. Chin J Cancer. 2012;31(4):185-96.

2. Thompson LR. Update on nasopharyngeal carcinoma. Head Neck Pathol. 
2007;1(1):81-6.

3. Barnes L, Eveson JW, Reicchart P, Sidransky D, editors. World Health Organization Classification of Tumours: pathology and genetics of head and neck tumours: Lyon: IARC Press;2005.

4. Cengiz K, Kumral TL, Yildirim G. Diagnosis of pediatric nasopharynx carcinoma after recurrent adenoidectomy. Case Rep Otolaryngol. 2013;2013:653963.

5. Chan AT, Gregoire V, Lefebvre JL, Licitra L, Hui EP, Leung SF, et al. Nasopharyngeal cancer: EHNS-ESMO-ESTRO clinical practice guidelines for diagnosis, treatment and follow-up. Ann Oncol. 2012;23 Suppl 7:vii 83-5.

6. Tabuchi K, Nakayama M, Nishimura B, Hayashi K, Hara A. Early detection of nasopharyngeal carcinoma. Int J Otolaryngol. 2011;2011:638058.

7. Piazza C, Del Bon F, Nicolai P. Narrow band imaging in endoscopic evaluation of head and neck mucosal cancer. J ENT Masterclass.2012; 5(1):59-64.

8. Lukes P, Zabrodsky M, Plzak J, Chovanec M, Betka J, Foltynova E, et al. Narrow band imaging-endoscopic method for detection of head and neck cancer. In: Amornyotin A, editor. Endoscopy. Intech; 2013. Available from: https://www.intechopen.com/ books/endoscopy/narrow-band-imagingnbi-endoscopic-method-for-detection-ofhead-and-neck-cancer

9. Piazza C, Dessouky O, Peretti G, Cocco D, De Benedetto L, Nicolai P. Narrow band imaging: a new tool for evaluation of head and neck squamous cell carcinomas. Acta Otorhinolaryngol Ital. 2008;28(2):49-54.

10. Thong JF, Ranjini KS, Loke D, Mok PKH. Use of narrow-band imaging in detection of nasopharyngeal carcinoma. J Laryngol Otol. 2013;127(2):163-9.

11. Kumar S. Epidemiological and etiological factors associated with nasopharyngeal carcinoma. ICMR Bull. 2003;33(9):1-9.

12. Nesic V, Sipetic S, Vlajinac H, Stosic-Divjak $\mathrm{S}$, Jesic S. Risk factors for the occurrence of undifferentiated carcinoma of nasopharyngeal type: a case-control study. Srp Arh Celok Lek. 2010;138(1-2):6-10.

13. Wang $\mathrm{WH}$, Lin $\mathrm{YC}$, Lee $\mathrm{KF}$, Weng $\mathrm{HH}$. Nasopharyngeal carcinoma detected by narrow-band imaging endoscopy. Oral Oncol. 2011;47(8): 736-41.

14. Wen YH, Zhu XL, Lei WB, Zeng YH, Sun YQ, Wen WP. Narrow-band imaging: a novel screening tool for early nasopharyngeal carcinoma. Arch Otolaryngol Head Neck Surg. 2012;138(2):183-8. 